\title{
Suriye İç Savaşı Sonrası Nizip'te Kutanöz Leyşmanyazis Olguları
}

\section{Cutaneous Leishmaniasis Cases in Nizip, Turkey After the Syrian Civil War}

\author{
İsmail Serkan SALMAN ${ }^{1}$, Ahmet VURAL ${ }^{2}$, Ahmet ÜNVER ${ }^{2}$, Suzan SAÇAR ${ }^{3}$ \\ ${ }^{1}$ Nizip Devlet Hastanesi, Tıbbi Mikrobiyoloji Laboratuvarı, Gaziantep. \\ ${ }^{1}$ Nizip State Hospital, Medical Microbiology Laboratory, Gaziantep, Turkey. \\ ${ }^{2}$ Çanakkale Onsekiz Mart Üniversitesi Tıp Fakültesi, Tıbbi Mikrobiyoloji Anabilim Dalı, Çanakkale. \\ ${ }^{2}$ Canakkale Onsekiz Mart University Faculty of Medicine, Department of Medical Microbiology, Canakkale, Turkey. \\ ${ }^{3}$ Çanakkale Onsekiz Mart Üniversitesi Tıp Fakültesi, Enfeksiyon Hastalıkları ve Klinik Mikrobiyoloji Anabilim Dalı, \\ Çanakkale. \\ ${ }^{3}$ Canakkale Onsekiz Mart University Faculty of Medicine, Department of Infectious Diseases and Clinical Microbiology, \\ Canakkale, Turkey.
}

Geliş Tarihi (Received): 05.08.2013 • Kabul Ediliş Tarihi (Accepted): 18.11.2013

\section{ÖZET}

Kutanöz leyşmanyazis (KL) birçok ülkede endemik olarak görülen, dünya genelinde yaygın bir protozoon hastalığıdır. Türkiye'nin komşuları olan İran, Irak ve Suriye gibi ülkeler ise KL için yüksek endemik bölgelerdir. Ülkemizde KL olgularını \%98'inden fazlası Güney ve Güneydoğu Anadolu bölgelerinden bildirilmektedir. Bu çalışmada, üç buçuk yıllık dönemde Nizip bölgesinde KL prevalansının belirlenmesi ve Suriye iç savaşı sonrası KL olgularında saptanan dramatik artışa dikkat çekilmesi amaçlanmıştır. Çalışmaya, 01.01.2010-19.03.2013 tarihleri arasında Nizip Devlet Hastanesi Mikrobiyoloji Laboratuvarına klinik KL şüphesi ile gönderilen 341'i Suriye mültecisi olmak üzere toplam 416 hasta örneği dahil edilmiştir. Hastalardan lezyon örnekleri Sağlık Bakanlığı genelgesine uygun olarak alınmış ve hazırlanan yayma preparatlar Giemsa ile boyanarak ışık mikroskobu (x1000) ile incelenmiştir. Mikroskopik incelemede Leishmania amastigot şekilleri görülen toplam 77 (\%18.5) hastaya KL tanısı konulmuştur. Hastaların 47 (\%61)'si kadın, 30 (\%39)'u erkek olup; 52 (\%67.5)'sinin 0-19 yaş, 13 (\%16.9)'ünün 20-39 yaş ve 12 (\%15.6)'sinin 40-60 yaş grubunda olduğu izlenmiştir. Lezyonların dağılımı incelendiğinde; 33 (\%43) hastada tekli, 44 (\%57) hastada ise çoklu lezyon varlığı tespit edilmiş; lezyonların sıklık sırasıyla yüz, kol ve alt ekstremitelerde bulunduğu gözlenmiştir. Lezyonların ortaya çıkma süresinin ortalama 3.4 ay (minimum 1.5 ay, maksimum 1 yıl) olduğu saptanmıştır. Kutanöz leyşmanyazisli hastalar yaş, cinsiyet ve lezyon özellikleri (sayısı, dağılımı, oluşum süresi) bakımından karşılaştııılığında istatistiksel olarak anlamlı bir ilişki saptanmamıştır (p> 0.05). Çalışmamızda 2010, 2011, 2012 ve 2013 (ilk üç ay) yıllarında Nizip'te saptanan yerli ve Suriye kökenli KL olgu sayıları sırasıyla; 1 ve 0,2 ve 0,7 ve 0,5 ve 62 olarak 
belirlenmiştir. Buna göre KL tanısı alan hastaların 15 (\%19.5)'inin Türk, 62 (\%80.5)'sinin Suriye kökenli olduğu gözlenmiştir. Ayrıca, hastaneye başvuran hastaların oranının çadır kentlerdeki mülteci nüfusuna göre oldukça az olması, hastalık insidansının belirlenenden çok daha fazla olabileceğini düşündürmüştür. Sonuç olarak verilerimiz, KL için iklim ve vektör potansiyeli açısından zaten elverişli olan Nizip ve çevresinin, Suriye iç savaşı sonrası mültecilerin yerleşimiyle, hastalığın yayılımında daha da büyük bir sağlık tehdidi oluşturduğunu göstermiş; etkin korunma ve kontrol yöntemlerinin alınması gerekliliğini ortaya koymuştur.

Anahtar sözcükler: Kutanöz leyşmanyazis; prevalans; mülteci; Suriye; Türkiye.

\begin{abstract}
Cutaneous leishmaniasis $(\mathrm{CL})$, seen endemically in many countries, is a widespread protozoon disease all around the world. The neighboring countries of Turkey namely Iran, Iraq and Syria are highly endemic regions for $\mathrm{CL}$, and more than $98 \%$ of the cases in Turkey are reported from South and Southeastern Anatolian regions. The aim of this study was to detect the prevalence of $\mathrm{CL}$ in Nizip, a district of Gaziantep province of southeastern Turkey, for three and half year period and to call attention to the dramatic increase of CL cases observed after the Syrian civil war. A total of 416 samples obtained from clinically suspected CL patients (of them 341 were Syrian refugees) who were admitted to Nizip State Hospital between January $1^{\text {st }} 2010$ and March $19^{\text {th }} 2013$ were included in the study. Lesion samples were collected according to the notice issued by Turkish Ministry of Health and Giemsa-stained smears were examined under the microscope $(x 1000)$. Samples from 77 patients $(18.5 \%)$ yielded positive results with the observation of Leishmania amastigote forms. Fourty-seven (61\%) of patients were female and 30 (39\%) were male. Of the positive patients $52(67.5 \%)$ belonged to 0-19 age group, 13 (16.9\%) 20-39 and 12 (15.6\%) 40-60 age groups. In the evaluation of the lesion characteristics, 33 (43\%) patients had single and $44(57 \%)$ had multiple lesions with a distribution mainly on face, arm and lower extremities, in a decreasing order. The period of time for the development of the lesions varied from 1.5 month to one year with the mean value of 3.4 months. There was no statistically significant relationship between the age and gender of patients, and the characteristics (quantity, distribution and time of occurence) of lesions ( $p>0.05$ ). The number of domestic and Syrian CL cases detected in Nizip in the years of 2010, 2011, 2012 and 2013 (the first three months) were as follows; 1 and 0,2 and 0 , 7 and 0,5 and 62 , respectively. So a total of $62(80.5 \%)$ and 15 (19.5\%) of CL patients were found to be Syrian refugees and Turkish citizens, respectively. Since the number of the cases admitted to the hospital was significantly low in comparison to the total population of refugees living in the camps, it was assumed that the real incidence of $C L$ was much higher than determined. The data obtained in this study revealed that Nizip and the surroundings which have already had favourable climate and vector potential for $\mathrm{CL}$, exhibited a higher threat for the spread of the disease following the hosting of the refugees. Thus implementation of effective prevention and control measures should be taken into consideration implemented in that specific area.
\end{abstract}

Key words: Cutaneous leishmaniasis; prevalence; refugee; Syrian; Turkey.

\title{
Giriş
}

Leyşmanyazis, yaklaşık 12 milyon kişinin enfekte olduğu, 350 milyon kişinin enfeksiyon riski taşıdığı, 98 ülkede endemik olarak görülen, dünya genelinde yaygın intraselüler protozoon olan Leishmania türlerinin neden olduğu önemli bir paraziter hastalıktır',2. Her yıl yaklaşık 2 milyon yeni leyşmanyazis olgusu bildirilmekte; bunlardan 1.5 milyon kadarının kutanöz olduğu tahmin edilmektedir. Kutanöz leyşmanyazis (KL) olgularının 
\%90'ından fazlası Afganistan, Cezayir, Brezilya, İran, Irak, Peru, Suudi Arabistan ve Suriye'de görülmektedir ${ }^{1,2}$. Komşumuz Suriye'de 2003-2004 yıllarında toplam 25.000 olgu/yıl, sadece Halep şehrinde ise $10.000^{\prime}$ in üzerinde yeni olgu bildirimi yapılmıştır ${ }^{3}$.

Türkiye'de KL olgularının \%98'inden fazlası Güneydoğu ve Güney Anadolu Bölgesinde bulunan altı şehirde (Şanlıurfa, Diyarbakır, Adana, Osmaniye, Hatay, İçel) düzenli olarak rapor edilmektedir ${ }^{4}$. Sağlık Bakanlığı verilerine göre son 20 yılda Türkiye'de görülen KL olgularının ortalama \%45'i Şanlıurfa'da görülmektedir ${ }^{5}$. Türkiye'de başta Güneydoğu illerimizde Leishmania tropica'nın sebep olduğu "antroponotik KL" gözlenmektedir. Bu türün bulaşı, enfekte insan-vektör-insan döngüsü şeklindedir ${ }^{5,6}$. Hastalığın vektörü olan erişkin tatarcık sineklerinin aktiviteleri ilkbaharın son dönemleri ve yaz başlangıcında başlar ve havalar soğuyuncaya kadar devam eder. Antroponotik KL'de enfekte bireyler hastalık etkeni için en önemli kaynağı oluşturmaktadır. Bunun yanı sıra, vektör tatarcıkların kullanılan insektisitlere direnç kazanması veya kalıcı insektisit uygulamasının etkin ve yeterli yapılamaması da hastalığın yaygınlaşmasında önemli rol oynamaktadır ${ }^{5}$. Ayrıca, yetersiz altyapı ile çarpık kentleşme KL için en önemli küresel risk faktörü olup, hastalığın özellikle antroponotik odaklardaki sürekliliğine katkıda bulunmaktadır ${ }^{7}$. Hastalığın endemik olduğu bölgelerde tanı klinik bulgulara göre yapılabilir. Kesin tanı klinik örneklerden amastigot formun saptanması ya da kültürde promastigotların görülmesiyle konulur. Tür tayini ve genotiplendirme amacıyla moleküler yöntemler uygulanırken, serolojik yöntemler daha ziyade araştırma ve epidemiyolojik amaçlı kullanılmaktadır ${ }^{8}$. Bu çalışmanın amacı, Nizip bölgesinde KL prevalansının belirlenmesi ve Suriye iç savaşı sonrası KL olgularında saptanan dramatik artışa dikkat çekilmesidir.

\section{GEREÇ ve YÖNTEM}

Çalışmaya, Nizip Devlet Hastanesi Mikrobiyoloji Laboratuvarına 01.01.201019.03.2013 tarihleri arasında klinik olarak KL şüphesiyle gönderilen 341'i Suriye mültecisi olmak üzere toplam 416 hastanın lezyonlarından, Sağlık Bakanlığı genelgesine uygun olarak alınan örnekler dahil edildi ${ }^{9}$. Örneğin alınacağı bölge \%70'lik alkol ile iyice temizlenip, bisturi ile lezyon kenarına $0.5 \mathrm{~mm}$ uzunluğunda, 2-3 mm derinliğinde bir insizyon yapıldı. Gazlı bez ile insizyon üzerindeki kan damlası temizlenerek, insizyonun iç kısmına insizyona dik olacak şekilde kazıma işlemi yapılarak seröz materyal alındı. Alınan materyal lam üzerine yayıldı; Giemsa ile boyandı ve mikroskobik olarak 100x immersiyon objektifiyle incelendi ${ }^{9}$.

Leishmania pozitif hastalar yaş, cinsiyet, lezyonların tekli veya çoklu oluşu ve lezyonların oluşum süresi gibi özellikler bakımından karşılaştırıldı; istatistiksel değerlendirmede ki-kare yöntemi kullanıldı.

\section{BULGULAR}

Araştırmamızda, mikroskobik incelemede Leishmania amastigot şekilleri görülen toplam 77 (77/416, \%18.5) hastaya KL tanısı konmuştur. Tanı konulan hastaların 62 (\%80.5)'sinin Suriye kökenli, 15 (\%19.5)'inin Türk olduğu belirlenmiştir. Hastaların yıllara ve uyruğuna göre dağılımı Tablo I'de; KL'li bir hastanın lezyon görüntüsü ile preparatında Leishmania amastigot formlarının gördüğü hastalardan birine ait pozitif sonuç ise Resim 1'de verilmiştir. 


\begin{tabular}{|lccc|}
\hline \multicolumn{4}{|l|}{ Tablo I. Kutanöz leyşmanyazisli hastaların yıllara ve uyruğuna göre dă̆ılımı } \\
\hline Yıllar & Yerli olgu & Suriye kökenli olgu & Toplam \\
\hline 2010 & 1 & 0 & 1 \\
2011 & 2 & 0 & 2 \\
2012 & 7 & 0 & 7 \\
2013 (ilk 3 ay) & 5 & 62 & 67 \\
Toplam & 15 & 62 & 77 \\
\hline
\end{tabular}

Leishmania pozitif hastaların anamnezleri doğrultusunda, lezyonların oluşum zamanının en kısa 1.5 ay, en uzun ise 1 yıl olduğu (ortalama 3.4 ay) tespit edilmiştir. Leishmania pozitif hastalar yaş, cinsiyet, lezyonların tekli veya çoklu oluşu ve lezyonların oluşum süresi özellikleri bakımından karşılaştırılmış ve gruplar arasında istatistiksel olarak anlamlı fark saptanmamıştır ( $\mathrm{p}>0.05$ ) (Tablo II).

Suriye kökenli hastaların tamamının Halep Bölgesi’nden Türkiye'ye giriş yaparak, burada sağlanan yardım kamplarında ikamet ettikleri belirlenmiştir. Türk hastaların ise 12'sinin Gaziantep-Nizip, diğer üçünün ise Gaziantep-Karkamış, Şanlıurfa-Birecik ve Şanlıurfa-Halfeti kökenli olduğu tespit edilmiştir.

\section{TARTIŞMA}

Dünyadaki KL sıklığına ait sayıların, özellikle gelişmemiş ülkelerdeki bildirim sisteminin zayıf olması ya da hiç olmaması ve yanlış/eksik tanı konulması gibi sorunlar nedeniyle gerçeğin çok altında olduğu tahmin edilmektedir. Dünya Sağlık Örgütü kayıtlarında yer alan veriler çoğunlukla pasif sürveyanslardan elde edilmişlerdir ${ }^{10}$. Dünyada halen $\mathrm{KL}$ açısından çok az hizmet alan veya hiç ulaşılamayan birçok hasta olduğu ve hastalarının

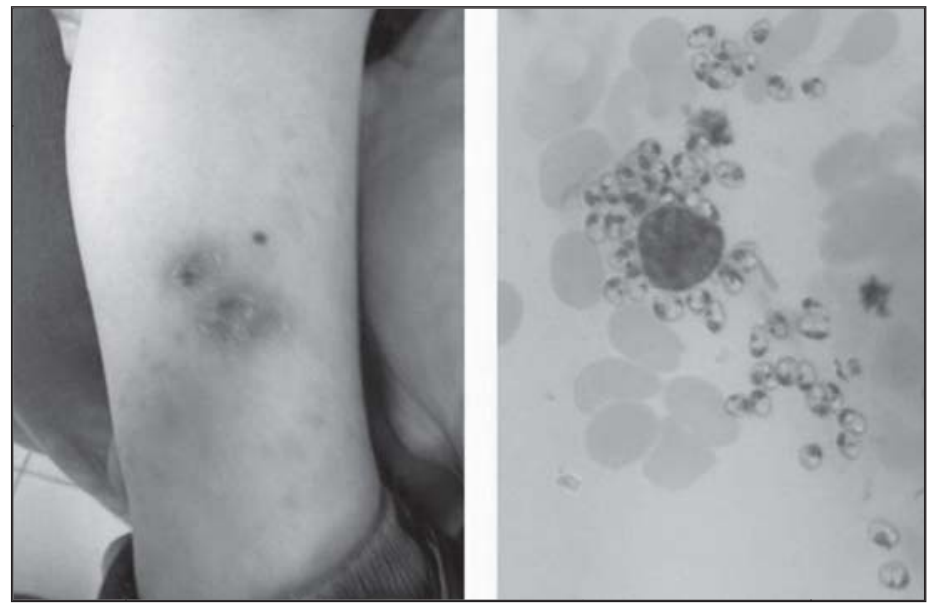

Resim 1. Kutanöz leyşmanyazisli bir hastanın lezyon görüntüsü (solda); pozitif bir hasta örneğinde gözlenen Leishmania amastigot formları (Giemsa, x1000) (sağda). 


\begin{tabular}{|c|c|c|c|c|}
\hline \multirow[b]{2}{*}{ Yaş grubu (Yıl) } & \multirow{2}{*}{$\begin{array}{c}\text { Kadın } \\
\text { Sayı (\%) }\end{array}$} & \multirow{2}{*}{$\begin{array}{c}\text { Erkek } \\
\text { Sayı (\%) }\end{array}$} & \multicolumn{2}{|c|}{ Lezyon sayısı (\%) } \\
\hline & & & Tekli & Çoklu \\
\hline $0-9$ & $21(27.3)$ & $17(22)$ & $17(22)$ & $21(27.2)$ \\
\hline $10-19$ & $7(9)$ & $7(9)$ & $7(9)$ & $7(9)$ \\
\hline $20-29$ & $4(5.1)$ & $2(2.6)$ & $2(2.6)$ & $4(5.1)$ \\
\hline $30-39$ & $6(85.7)$ & $1(1.3)$ & $1(1.3)$ & $6(85.7)$ \\
\hline $40-49$ & $4(5.1)$ & 0 & $2(2.6)$ & $2(2.6)$ \\
\hline $50-59$ & $4(5.1)$ & $3(3.9)$ & $4(5.1)$ & $3(3.9)$ \\
\hline$>60$ & $1(1.3)$ & 0 & 0 & $1(1.3)$ \\
\hline Toplam & $47(61)$ & $30(39)$ & $33(43)$ & $44(57)$ \\
\hline
\end{tabular}

\%50'sinden fazlasının uygun tanı ve tedavi alamadığı düşünülmektedir ${ }^{11,12}$. Bu durum; endemik ülkelerin çoğunun fakir ülkeler olması, leyşmanyazisin öncelikli sağlık problemi olarak kabul görmemesi ve bazı sivil toplum kuruluşları dışında kontrol programlarının fonksiyonel olarak sürdürülememesi gibi faktörlerden kaynaklanmaktadır.

Antroponotik KL Güneydoğu Anadolu Bölgesi'nde özellikle Şanlıurfa ilinde hiperendemik, Çukurova bölgesinde ise endemik bir hastalık olarak yıllardır varlığını sürdürmektedir $^{4,13}$. Ayrıca, son yıllarda Birecik ilçe merkezinden de $\mathrm{KL}$ olguları bildirilmektedir ${ }^{5}$. Bu çalışmada 2010, 2011 ve 2012 yıllarında Gaziantep'in Nizip bölgesinde düşük olan pozitif hasta sayısının, 2013 yılının ilk çeyreğinde dramatik artış gösterdiği ve bu durumun Suriyeli mültecilerin bölgeye intikali ile eş zamanlı olduğu dikkati çekmiştir. Çalışma süresince hastalarla yapılan görüşmelerde bölgeye sağlık hizmeti ulaşması konusunda ciddi sıkıntılar olduğu anlaşılmakta ve bu iç savaş ortamında KL gibi hastalıkların önemsenmediği açıkça görülmektedir. Ayrıca, hastaneye başvuran hastaların oranının çadır kentlerdeki nüfusa göre oldukça az olması, hastalığın yaygınlığının belirlenenden çok daha fazla olabileceğini düşündürmektedir.

Kutanöz leyşmanyazisin epidemiyolojisinde sosyoekonomik, politik ve çevresel faktörler belirleyici rol oynamaktadır. Kentler arası ulaşımın yaygınlaşması, göçlerin artışı, kaynak olguların tedavi edilmemesi, vektörle düzenli mücadele yürütülememesi ve sağlıksız kentleşme gibi faktörler enfeksiyon insidansının artışında etkilidir ${ }^{14}$. Lezyonların ağrısız olması, bir yıl içinde kendiliğinden iyileşebilmesi ve sistemik komplikasyonlara neden olmaması da, hastalığın toplum tarafından kabul edilmesine neden olmaktadır. Ancak KL tanısı konulan tüm hastalardaki tedavi gerekliliği bilinmektedir. Erken tedavi ile enfeksiyon zincirinin kırılması, yeni olguların önlenmesi ve yeni enfeksiyon alanlarının oluşmasını engelleyebilir. KL epidemiyolojisinde iklim özellikleri de önemli rol oynamakta, bulaşın, tatarcıkların aktif olduğu Nisan-Eylül ayları arasında olduğu, çoğunlukla da sıcak geçen Haziran-Ağustos arasında gerçekleştiği bildirilmektedir ${ }^{4,15,16}$. Ayrıca, konut- 
ların çamurdan ve sağlıksız olduğu, insanların evlerinin dışında uyuma alışkanlığının olduğu ve vektör tatarcıkların büyük popülasyonlar oluşturdukları bölgelerde KL sıklığının artabileceği vurgulanmaktadır ${ }^{17}$. Bizim çalışmamızda KL olgularının Nizip bölgesinde saptanmış olması, hastalıkla mücadelede bulaş yollarının ve risk faktörlerinin kontrol altına alınması gerekliliğini ortaya koymaktadır. On binden fazla kişiyi barındırmakta olan mülteci kampları Fırat nehrine oldukça yakın bir yerleşkededir. Bu alan başta Birecik ilçe merkezinin ve Şanlıurfa köylerinin bulunduğu, halen KL açısından hiperendemik bir bölgedir. Hasta bilgilerine göre yaz aylarında balkon ve çatılarda uyuma gibi bulaş açısından riskli davranışlarda bulunmaları, bölgedeki yerleşim birimlerinin sağlıklı çevresel şartlarda olmaması ve özellikle 2013 yılının yaz aylarında vektör tatarcıkların hayat döngüsü hastalığın yayılması açısından büyük risk oluşturmaktadır. Ayrıca, bazı mültecilerin kamp dışına çıkarak şehir içine yerleşmeleri enfeksiyon riskini oldukça artırmaktadır.

Türkiye'de sık görülen L.tropica'nın inkübasyon süresi iki aydan az, L.major'ün inkübasyon süresi ise iki aydan fazla olup, papül gelişimin en az birkaç haftada gerçekleştiği ve iyileşmenin L.major için 2-6 ay, L.tropica için ise 8-12 ay olduğu belirtilmiştir ${ }^{18}$. Bu çalışmada eritemli papül şeklinde lezyonların 2-3 aydır bulunduğu tespit edilmiştir. Hastaların çoğunun Suriye kökenli olması ve olası etken L.major'ün inkübasyon, enfeksiyon ve iyileşme süreleri göz önüne alındığında, aynı zamanda hastaların başvurduğu tarihin 2013 yılının Şubat ve Mart ayları olması henüz hastanelere başvurmayan buna benzer olguların yüksek olabileceğini düşündürmektedir. Vektör sineklerin biyolojisi hastalığın tüm bölgeye yayılabilme riskini artırmakla beraber, endemik bölgeye olan insan hareketleri düşünüldüğünde gerekli önlemlerin ivedilikle alınmaması durumunda, hastaı̆ğın yayılımının sadece Güneydoğu Anadolu Bölgesi ile sınırlı kalmaması muhtemeldir.

Çalışmamızda, KL'li hastalarda yaş, cinsiyet, lezyonların sayısı ve oluşum süresi gibi özellikler açısından istatistiksel olarak anlamlı bir ilişki saptanmamış ( $p>0.05)$ ve bu durum Votypka ve arkadaşlarının ${ }^{19}$ verileriyle uyumlu bulunmuştur.

Kutanöz leyşmanyazisin laboratuvar tanısında bazı ciddi sorunlar mevcuttur. Tanı için örneğin alınma şekli, lezyonun sekonder etkenlerle enfekte olma riski, yaymaları inceleyen kişinin deneyimi, birden fazla lezyonu olanlarda örneğin hangisinden alınacağına karar verilmesi gibi durumlar tanı başarısını etkilemektedir. Buna karşın alınan örneklerin Giemsa ile boyanması gibi basit ve ucuz bir yöntemin, deneyimli kişilerce hızlı ve ekonomik bir tanı aracına dönüşebileceği ve \%53.3-\%84.2 aralığında duyarlılık gösterebileceği belirtilmiştir ${ }^{20,21}$. Ranawaka ve arkadaşları ${ }^{22} \mathrm{da}$, endemik bölgelerde dermatoloğun klinik tanısı ile birlikte, bunu destekleyen, lezyondan yayma yöntemleri gibi basit, ucuz ve pratik testlerin \%96'ya varan duyarlılık gösterdiğini ifade etmişlerdir. Bizim çalışmamızda, klinik olarak KL şüpheli hastaların lezyon örneklerinden hazırlanan Giemsa boyalı yaymaların direkt mikroskopik incelemesinde amastigotların görülmesi sonucu Leishmania spp. tanısı konulmuş; ancak tür tayini için ileri yöntemlerin kullanılması mümkün olamamıştır. Direkt mikroskopik incelemenin en önemi dezavantajı, tür düzeyinde ayırım yapılamamasıdır. Oysa moleküler yöntemler ile tür düzeyinde tanımlama ve genotiplendirmenin yapılması, gerek hastalığın epidemiyolojisi, gerek prognozun takibi, gerekse tedavi başarısı için son derece önemlidir ${ }^{23-25}$. 
Sonuç olarak verilerimiz, KL için iklim ve vektör potansiyeli açısından zaten elverişli olan Nizip ve çevresinin, Suriye iç savaşı sonrası mültecilerin yerleşimiyle, hastalığın yayılımında daha da büyük bir sağlık tehdidi oluşturduğunu göstermiş;; etkin korunma ve kontrol yöntemlerinin alınması gerekliliğini ortaya koymuştur.

\section{KAYNAKLAR}

1. Den Boer M, Argaw D, Jannin J, Alvar J. Leishmaniasis impact and treatment access. Clin Microbiol Infect $2011 ; 17(10): 1471-7$.

2. Alvar J, Velez ID, Bern C, et al; WHO Leishmaniasis Control Team. Leishmaniasis worldwide and global estimates of its incidence. PLoS One 2012; 7(5): 35671.

3. World Health Organization. Report of the consultative meeting on cutaneous leishmaniasis. 2008, WHO Document Production Services, Geneva. WHO/HTM/NTD/IDM/2008.7 http://www.who.int/leishmaniasis/ resources/Cutaneous_leish_cm_2008.pdf

4. Ok UZ, Balcioğlu IC, Taylan Ozkan A, Ozensoy S, Ozbel Y. Leishmaniasis in Turkey. Acta Trop 2002; 84(1): 43-8.

5. Gürel MS, Yeşilova Y, Ölgen MK, Özbel Y. Cutaneous leishmaniasis in Turkey. Turkiye Parazitol Derg 2012; 36(2): 121-9.

6. Ertem M, Aytekin S, Acemoğlu H, Akpolat N, Aytekin N. Diyarbakır Dicle ilcçesi Dedeköy ve Durabeyli'de kutanöz leishmaniasis olgularının incelenmesi. Türkiye Parazitol Derg 2004; 28 (2): 65-8.

7. World Health Organization. Urbanization: an increasing risk factor for leishmaniasis. Wkly Epidemiol Rec 2002; 77(44): 365-70.

8. Bruckner DA, Labarca VA. Leishmania and Trypanosoma, pp: 1721-7. In: Murray PR, Baron EJ, Jorgensen JH, Landry ML, Pfaller MA (eds). Manual of Clinical Microbiology. 2009, $9^{\text {th }}$ ed. American Society for Microbiology, Washington DC.

9. T.C. Sağlık Bakanlığı Temel Sağlık Hizmetleri Genel Müdürlüğü. Kutanöz Leishmaniasis. 2003/126 Sayılı Daimi Genelge, 2003. http://www.shsm.gov.tr/public/documents/legislation/bhkp/bh/zoonotik/leishmaniasis/KutanozLeishmaniasisGenelgesi.pdf

10. Desjeux P. Leishmaniasis public health aspects and control. Clin Dermatol 1996; 14(5): 417-23.

11. Ahluwalia IB, Bern C, Costa C et al. Visceral leishmaniasis: consequences of a neglected disease in a Bangladeshi community. Am J Trop Med Hyg 2003; 69(6): 624-8.

12. Alvar J, Yactayo S, Bern C. Leishmaniasis and poverty. Trends Parasitol 2006; 22(12): 552-7.

13. Ozbel Y, Turgay N, Ozensoy S, et al. Epidemiology, diagnosis, and control of leishmaniasis in Mediterranean region. Ann Trop Med Parasitol 1995; 89(1): 89-93.

14. Özcel MA. GAP ve Parazit Hastalıkları. 1993, Türkiye Parazitoloji Derneği, Yayın No: 11, İzmir.

15. Uzun S, Durdu M, Culha G, Allahverdiyev AM, Memisoglu HR. Clinical features, epidemiology, and efficacy and safety of intralesional antimony treatment of cutaneous leishmaniasis: recent experience in Turkey. I Parasitol 2004; 90(4): 853-9.

16. Alten B, Çağlar SS. Vektör Ekolojisi ve Mücadelesi. 1998, Sağlık Bakanlığı Yayını, Ankara.

17. Kadaro AY, Ghalib HW, Ali MS, et al. Prevalence of cutaneous leishmaniasis along the Nile River north of Khartoum (Sudan) in the aftermath of an epidemic in 1985. Am J Trop Med Hyg 1993; 48(1): 44-9.

18. Afghan AK, Kassi M, Kasi PM, Ayub A, Kakar N, Marri SM. Clinical manifestations and distribution of cutaneous leishmaniasis in Pakistan. J Trop Med 2011; 2011: 359145.

19. Votypka J, Kasap OE, Volf P, Kodym P, Alten B. Risk factors for cutaneous leishmaniasis in Cukurova region, Turkey. Trans R Soc Trop Med Hyg 2012; 106(3): 186-90.

20. ul Bari A, ber Rahman S. Correlation of clinical, histopathological, and microbiological findings in 60 cases of cutaneous leishmaniasis. Indian J Dermatol Venereol Leprol 2006; 72(1): 28-32. 
21. Al-Hucheimi SN, Sultan BA, Al-Dhalimi MA. A comparative study of the diagnosis of Old World cutaneous leishmaniasis in Iraq by polymerase chain reaction and microbiologic and histopathologic methods. Int J Dermatol 2009; 48(4): 404-8.

22. Ranawaka RR, Abeygunasekara PH, Weerakoon HS. Correlation of clinical, parasitological and histopathological diagnosis of cutaneous leishmaniasis in an endemic region in Sri Lanka. Ceylon Med J 2012; 57(4): 149-52.

23. Khademvatan S, Neisi N, Maraghi S, Saki J. Diagnosis and identification of Leishmania spp. from Giemsastained slides, by real-time PCR and melting curve analysis in south-west of Iran. Ann Trop Med Parasitol 2011; 105(8): 559-65.

24. Schriefer A, Wilson ME, Carvalho EM. Recent developments leading toward a paradigm switch in the diagnostic and therapeutic approach to human leishmaniasis. Curr Opin Infect Dis 2008; 21(5): 483-8.

25. Croft SL, Sundar S, Fairlamb AH. Drug resistance in leishmaniasis. Clin Microbiol Rev 2006; 19(1): 111-26. 